\title{
Wechselwirkungskräfte und Renormalisation in der Photonpaar-Theorie
}

\section{Doctoral Thesis}

Author(s):

Enz, Charles Paul

Publication date:

1956

Permanent link:

https://doi.org/10.3929/ethz-a-000091745

Rights / license:

In Copyright - Non-Commercial Use Permitted 
Prom. ${ }_{\text {. }}{ }_{2556} \beta . \quad$ Diss ETH

\title{
WECHSELW IRKUNGSKR ÄFTE UND RENORMALISATION IN DER PHOTONPAAR-THEORIE
}

\author{
VON DER \\ EIDGENÖSSISCHEN TECHNISCHEN \\ HOCHSCHULE IN Z̈ÜRICH \\ ZUR ERLANGUNG \\ DER WURDE EINES DOKTORS DER \\ NATURWISSENSCHAF'TEN \\ GENEHMIGTE \\ PROMOTIONSARBEIT \\ VORGELEGT VON \\ CHARLES PAUL ENZ \\ VON IIERISAU (AR)
}

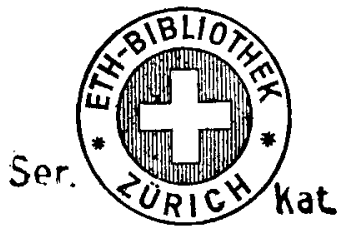

Referent: Herr Prof. Dr. W. PaUli Korreferent: Herr Prof. Dr. G. Busch

NICOLA ZANICHELLI - BOLOGNA 
The unrelativistic quantum electrodynamics of heavy particles with extended charge (radius $a$ ) is formulated in momentum space and in the Schrödinger representation, neglecting radiation recoil. After elimination of the longitudinal field and a trivial Bloch-Nordsieck transformation, the kinetic energy

$$
\sum_{n} \frac{1}{2 m_{0}}\left(\boldsymbol{p}_{n}-\boldsymbol{e A}(n)\right)^{2} \quad(\hbar=c=1
$$

still contains a field independent term and a term quadratic in the field. For infinite separation of all particles, the first term reduces to $\sum \boldsymbol{p}_{n}^{2} / 2 m$ if the mass is renormalized according to

$$
m=m_{0}+(4 / 3) \cdot E_{\text {coul }} \quad\left(E_{\text {coul }}=\text { Coulomb self energy }\right)
$$

where the electromagnetic mass $(4 / 3) \cdot E_{\text {coul }}$ is the same as in the classical theory of the electron. The quadratic term describes the interaction with the photon field and yields an additional self energy as well as forces between the particles. From the $r^{-3}$ dependence of the two body force, it follows that Coulomb's law remains unmodified for large separation $(r \gg a)$, so that there is no charge renormalization at all and for the coupling constant $r_{c}=e^{2} / 6 \pi m$ there remains only the mass renormalization which is effected according to

$$
\frac{1}{r_{c}}=\frac{1}{r_{c 0}}+\frac{1}{a}
$$

For $r_{c}>a\left(r_{c 0}<0\right)$ a pathological term, which prevents the definition of the photon vacuum, appears in the Hamiltonian. Without this term, however, the renormalized expression for the two body potential

$$
W(r)=-\frac{9}{8 \pi} \frac{r_{c}^{2}}{r^{3}}
$$

retains physical meaning. The same is true of the renormalized scattering cross-section; in particular, one obtains the classical Thomson formula (with damping) in the limiting case of a single point electron $(a \rightarrow 0)$. A generalized transformation to principal axes is developped to treat the scattering problem. 